\title{
A Case Study of the Marketing Tools Coffee Shop Owners Use to Sustain Businesses
}

\author{
Abi Adeleke \\ Walden University, Minneapolis, MN, USA \\ Email: aadeleke@gmail.com
}

How to cite this paper: Adeleke, A. (2020) A Case Study of the Marketing Tools Coffee Shop Owners Use to Sustain Businesses. Open Journal of Business and Management, 8, 726-753.

https://doi.org/10.4236/ojbm.2020.82044

Received: February 18, 2020

Accepted: March 15, 2020

Published: March 18, 2020

Copyright (c) 2020 by author(s) and Scientific Research Publishing Inc. This work is licensed under the Creative Commons Attribution International License (CC BY 4.0).

http://creativecommons.org/licenses/by/4.0/

(c) (i) Open Access

\begin{abstract}
The purpose of this multiple case study was to explore what marketing strategies some coffee shop owners use to sustain business operations during the first 5 years of operation. The targeted population consisted of 5 coffee shop owners in Arkansas who successfully implemented marketing strategies to sustain business operations during the first 5 years of operation. Goldsmith's 8Ps of marketing mix was the conceptual framework used in the study. Data were collected from semistructured interviews and a review of publicly available data and company websites. Data analysis occurred using the principles of the content analysis method, which included identifying codes and themes. Findings indicated owners of successful coffee shops were actively engaged in the day-to-day business operations and in the community; provided premium products; used social media for marketing, promotion, and branding; used competitive pricing; were precise about the location; provided exceptional customer service and personalization, and had points of marketing differentiation to promote their brand. The implications of this study for positive social change include the potential to support the welfare of the citizens of Arkansas, and owners of coffee shops across the United States that could provide independent coffee shop owners with marketing strategies necessary to sustain business operations, contribute to new job creation and regional economic sustainability.
\end{abstract}

\section{Keywords}

Business Failure, Business Success, Marketing Strategies, Small Business, Small Business Owner, US Small Business Administration (SBA)

\section{Introduction and Background}

Failure is an issue with small business owners globally [1]. Business failure is the 
termination of participation in an undertaking because it has not met a minimum threshold for economic survival envisaged by the business owner [2] [3]. Some small business owners lack knowledge of business administration including marketing strategies and technology to survive in small business [4] [5] [6]. The purpose of this study is to provide coffee shop owners with marketing strategies to sustain business operations during the first 5 years of operation. Understanding how to market the coffee shop business effectively can increase the ability of coffee shops to survive during the first 5 years of operation.

Survival is an issue with small businesses. In the second quarter of 2015, 234,000 businesses started up; in the same period, 213,000 business owners faced demise in the United States [7]. In the state of Arkansas, there were 6437 establishments with less than 100 employees [8]. Coffee shops (on-premise brewing) belong to the same North American Industry Classification System (NAICS) description code $(722,515)$ as snacks and nonalcoholic beverages bars [9]. In the second quarter of 2015, 1893 businesses started up, and in the same period, 1765 business owners experienced demise in the state of Arkansas [7]. Documentation from government agencies does not exist on the closure of coffee shops. However, Starbucks, the largest coffee shop company, has closed 443 stores throughout the company history: 240 stores in 2009, 42 in 2010, and 161 in 2011 [10]. Scholars have asked whether a marketing plan incorporating an element of personal branding, perseverance, practice, and coproduction, may assist owner-managers in surviving in small businesses [11].

\subsection{Problem Statement}

Coffee shop owners find difficulty to remain in business because of intense competition and the vagaries of customer preferences [12]. Only 54\% of small businesses, including coffee shops, opened in the United States in 2012, managed to remain in business longer than 5 years [13]. The general business problem is that some small business owners are unable to survive during the first 5 years of operation. The specific business problem is that some coffee shop owners lack the marketing strategies to sustain business operations during the first 5 years of operation.

\subsection{Purpose Statement}

The purpose of this qualitative multiple case study was to explore what marketing strategies some coffee shop owners use to sustain business operations during the first 5 years of operation. The targeted population consisted of five coffee shop owners in northwest Arkansas who successfully implemented marketing strategies to sustain business operations during the first 5 years of operation. Positive social change may result in a reduction in the number of coffee shop failures, thus improving employees' worth and dignity, and reducing the unemployment rates, which can result in building stronger communities through gainful employment. 


\subsection{Research Question}

The Central Research Question guiding this study was what marketing strategies do some coffee shop owners use to sustain business operations during the first 5 years of operation? Data derived from open-ended semistructured questions, participant observation, and non-participant observation for example, data from social media platforms of the coffee shops, and publicly available data.

\section{Assumptions, Limitations, and Delimitations}

\subsection{Assumptions}

Assumptions are facts the researcher of a study assumes as true [14]. I made three assumptions in this study. My first assumption was that coffee shop owners would provide adequate and truthful responses during the interviews. My second assumption was that the participants would share useful information on their marketing strategies. My final assumption was that the sample size of 5 coffee shop owners in the study was adequate for a multiple case study.

\subsection{Limitations}

Researchers must align with some limitations in their studies and the present study is no exception. Arbussa, Bikfalvi, and Marquès (2017) [15] explained that the researcher of a study of small-medium enterprises might need to overcome some of the sized-caused limitations. One of the limitations of my study was the choice of a multiple case study, which may not represent all information possible from studies with more subjects from the same industry [16]. The second limitation of my study was that the sample size was small and was from only the state of Arkansas.

Successful coffee shop owners might limit the research scope due to my exclusion of unsuccessful coffee shop owners. An exploratory multiple case study of five small business owners of coffee shops from Arkansas may not yield enough data to answer the research question and may not be representative of the population of coffee shop owners in the United States or other countries. The findings of the study may not apply to small businesses with over 100 employees. The third limitation of my study may include the specified area (northwest Arkansas and metropolitan area of Little Rock, Arkansas) for the study location. I may not be able to generalize the information gathered from this study to locations with high population densities. The final limitation of my study was that the interviewees might not be willing to share in-depth marketing strategy information in an interview setting.

\subsection{Delimitations}

Delimitations are limits purposely presented or placed by the researcher to restrict the scope of the study [17] [18]. The first delimitation was that the study participants were from the coffee shop industry and excluded other small businesses and services. Other delimitations of this study included the sample size, 
population, and the location of Arkansas. I focused on successful coffee shop owners because I was interested in the coffee shop industry. I gathered data from the owners regarding the marketing strategies they used to run successful coffee shops. The final delimitation was that I only interviewed small business owners who had successfully used marketing strategies to sustain business operations during the first 5 years of operation.

\section{Significance of the Study}

\subsection{Contributions to Business Practice}

The findings from a qualitative case study may add value to the business community by documenting how coffee shop owners use marketing strategies to sustain business operations during the first 5 years of operation. Coffee shop owners may benefit from study findings in providing awareness on becoming successful. Learning from successful coffee shop owners may provide insights to help potential coffee shop owners in adopting a successful marketing strategy during the first 5 years of operation. Finding the right value proposition that is successful during the first 5 years of operation includes the consideration of the traditional marketing mix elements of product, price, place, and promotion as well as the newer elements of participants, physical evidence, and process [19]. The knowledge obtained from study outcomes could benefit potential coffee shop owners through a better understanding of traditional and more contemporary marketing strategies, which may increase the businesses' survivability and contribute to beneficial social change.

The knowledge gained about the marketing strategies used by coffee owners to sustain business operations during the first 5 years of operation could provide awareness of the survivability of other coffee businesses. With effective marketing strategies, coffee shop owners could better appeal to customers in their marketplace. Other coffee shop owners can adopt these insights to increase better or sustain sales.

\subsection{Implementations for Social Change}

The potential social change benefits from the study include sustained employment of coffee shop employees in Arkansas, which can improve self-worth and human dignity for employed individuals. Small business coffee shop owners may find study outcomes so helpful that they hire more employees in Arkansas. Also, increased business and employment may result in more tax revenues for communities, which can help local citizens.

\section{A Review of the Academic Literature}

\subsection{Ps of Marketing Mix Theory}

The 8Ps marketing mix of Goldsmith (1999) [20] was the conceptual framework for this research study. Goldsmith developed the 8Ps of marketing mix theory. Goldsmith determined that personalization of products could set a brand apart 
from its competitors. Goldsmith emphasized the importance of the 8Ps of the marketing mix to carry marketing theory and practice into an era of personalization. The crux of Goldsmith's argument for the relevance of the 8Ps, was the need for managers to create marketing strategies which featured personalization alongside McCarthy's (1960) [21] traditional 4Ps (product, price, promotion, place), Booms's and Bitner's (1981) [22] 7Ps (adding personnel, physical evidence, and process), to form an innovative marketing mix, the eighth P. Mukherjee and Shivani (2016) [19] argued that the traditional marketing mix elements of product, price, place, and promotion were inadequate in achieving the marketing objectives in services. Furthermore, Pomering (2017) [23] suggested that small business owners who use the marketing mix could benefit by recalibrating the traditional $4 \mathrm{Ps}$ to a changing, sustainable society.

The coffee shop owner's use of the 8Ps of marketing mix, which includes personalization, could provide a unique positioning and marketing strategy in achieving a competitive advantage over competitors and sustaining business operations. Therefore, Goldsmith's (1999) [20] 8Ps of marketing mix conceptual framework could provide a means for exploring and understanding the marketing strategies that coffee shop owners use to sustain business operations during the first 5 years of operation.

\subsection{Small Businesses}

In the United States, the role of small businesses in the economy is significant. According to the Office of Advocacy, a small business has two unique features, 1) independent, and 2) has fewer than 500 employees [24]. Small business success is crucial to the stability of society and the economy, particularly the local economy and job creation [25] [26]. According to the SBA officials (2018), small businesses make up $99.9 \%$ of US employer firms, $99.7 \%$ of firms with paid employees, $48.0 \%$ of private sector workers, and $41.2 \%$ of private sector.

\subsection{History of the Marketing Mix Theory}

Neil Borden invented the term marketing mix in his 1953 American Marketing Association presidential address and formalized it in his Borden (1964) [27] article. Borden based the marketing mix phrase on a suggestion of a colleague's article [28] on the marketer as a mixer of ingredients. The original marketing mix framework consisted of 12 elements.

The 12 elements of Borden's marketing mix were: 1) product planning, 2) price planning, 3) brand, 4) channels of distribution, 5) personal selling, 6) advertising, 7) promotion, 8) packaging, 9) display, 10) servicing, 11) physical handling, and 12) fact-finding and analysis. Borden also developed a list of four elements of the marketing mix of manufacturers: a) consumers' buying behavior, b) trade behavior, c) competitors' position and behavior, and d) government behavior. In the short term, the use of the marketing mix shows marketers how to determine the allocation of expenditures among the different elements in ef- 
fective marketing methods. In the long term, the marketer can use the marketing mix to design a combination of marketing ingredients based upon long-range planning to ensure business owners successfully meet the demands of the changing marketplace. Mutandwa, Taremwa, and Tubanambazi (2015) [29] asserted one of the factors that determined the performance of small and medium enterprises is marketing. Therefore, a small business owner must employ marketing skills to ensure sustenance of business operations.

\subsection{Customer Relationship Management as a Means of Promoting the Business}

The essence of customer relationship marketing (CRM) is the interactions between the buyer and seller. Customer relationship management is a vital strategy for business success. Hidayanti, Herman, and Farida (2018) [30] posited that the rapid development of the Internet had accelerated the transition from traditional means of customer relationship management towards electronic Internet customer relationship management. Smaller companies have close interaction with customers. Small business owners can leverage this relationship to promote their businesses, strengthen customer loyalty, and increase customer retention beyond the limits of one-time transactions. Zhang, Watson, Palmatier, and Dant (2016) [31] noted that the understanding and managing of customer relationships are central in the marketing of businesses.

Consumers' loyalty contributes significantly to the long-term sustenance of a business [32]. Utami et al. found that coffee shop operators experienced higher customer loyalty because of higher service quality. Moreover, Marek (2014) [33] posited that business owners could more easily focus on promoting their brands and customer loyalty than larger competitors because of the limited geographical market coverage of small-to-medium size enterprises.

\section{Research Method and Design}

\subsection{Research Method}

Researchers use the qualitative research method to gain a holistic view of the topic via documents, observations, and interviews [34]. Yin (2017) [16] stated that utilizing an interview method with open-ended questions is valuable for gathering data from the participants. Also, with the qualitative method, I gained an understanding of the perspective of the participants through observation and interpretation. I saw an advantage of using a qualitative approach as the opportunity to gain valuable insights into the reasoning behind an occurrence or problem. I used the qualitative methodology to explore the research question: What marketing strategies do some successful coffee shop owners use to sustain business operations during the first 5 years of operation?

\subsection{Research Design}

I used semistructured interviews to explore successful marketing strategies that 
some coffee shop owners have used to sustain business operations during the first 5 years of operation. Researchers use a case study design to understand complex phenomena [35]. Yin (2017) [16] noted that a case study design is an approach for in-depth exploration of a study's problem and lends itself to the opportunity for future research. Yin (2017) [16] further noted the 5 components of case study research design were 1) the study questions, 2) the propositions, 3) the data analysis, 4) linking the data to the propositions, and 5) the criteria for interpreting the findings of the study. Using a case study design may help the researcher explore strategic management areas via face-to-face semistructured in-depth interviews and research questions (Gaya \& Smith, 2016) [36]. Gaya and Smith further outlined the importance of ensuring rigor in a qualitative study. The researcher using a case study design must understand the importance of choosing key informants, following the case study protocol, rigorous data collection, and analysis methods (including the ability to ask pertinent questions), facilitating triangulation of sources, and reporting of findings to increase the study's validity and the reliability of the data collected. The importance of achieving rigor in qualitative research mirror those of Noble and Smith (2015) [37] covering credibility, transferability, data dependability, and confirmability.

\subsection{Population and Sampling}

Once I settled on the methodology and research design, I selected the appropriate sample for the study. Gentles, Charles, Ploeg, and McKibbon (2015) [38] defined sampling in qualitative research as the selection of precise data sources from which the researcher collects data to address the research objectives. In a research study, the research question determines the sample size. Therefore, the selection of the participants is a qualitative case study is an important decision. Fletcher, Massis, and Nordqvist (2016) [39] noted that case study sampling inextricably links to the understanding of the investigated phenomenon.

I used the purposive sampling method, to select the participants. The rationale for using a purposive strategy was that I assumed that the participant had an in-depth understanding of the phenomenon of study. Parveen, Jaafar, and Ainin (2015) [40] noted that researchers use purposive sampling target participants to gain a more in-depth insight into the phenomenon of study. Fusch and Ness (2015) [41] further posited the researcher should choose the sample size that has the best prospect for the researcher to reach data saturation. I selected the owner from each of 5 coffee shops located in Arkansas who used marketing strategies to sustain their business operation in the first 5 years of operation.

\subsection{Data Collection Instrument}

The researcher is the primary data collection instrument in qualitative research [42]. For this qualitative case study, I am the primary data collection instrument and cannot separate myself from the research. As the researcher, I am operating in the world of the study participants as well as in the world of my perspective 
about the study. Therefore, I am an active participant in the research process. I collected data through in-depth interviews, participant observation, and non-participant observation as recommended by Gudkova (2017) [43]. The interview is the most effective method of data collection for qualitative studies [16]. Yin stated that a good interviewer should know the areas of technical and interaction competence. In qualitative research, the researcher uses interview questions structured, but open-ended questions as the primary source of data for an in-depth understanding of the phenomenon [44]. Furthermore, I used member checking as suggested by Birt, Scott, Cavers, Campbell, and Walter (2016) [45] to aid in enhancing the reliability and validity of the data collection instruments and ensuring an accurate representation of participants' views. Member checking is the method of returning a written summary of the interview to the SB to check (validate) its accuracy [45]. Upon completion of the study, I added the interview protocol and interview questions to the appendices.

\subsection{Data Collection Technique}

I collected the data for my study by contacting selected coffee shop owners to determine their suitability. Upon IRB approval, I contacted the pool of potential participants using e-mail to introduce myself and communicate the objective of the study. Next, I scheduled a phone meeting to explicate the study. After selecting potential participants, I provided the participants with the informed consent form for their review and signing. Once I obtained the signed consent form, I scheduled a time and location for each interview. Before each interview, I sent the participant a copy of the questions to ensure they are familiar with the questions and asked them to address their concerns. The participants did not receive any incentive to participate in the study.

I used open-ended semistructured questions in the interview process as the primary source of data for an in-depth understanding of the phenomenon as suggested by Parsa et al. (2015) [44]. The interview comprised 11 open-ended questions aligned with the research question. I conducted one-on-one interviews at times and locations convenient to each participant, recorded each participant's interview using Audacity, and downloaded the audio file. After completing the interview, I followed the recommendations of Silverman (2017) [46] and transcribed each audio recording to ensure I captured each participant's complete interview. Member checking include presenting the transcript summary to the participants and providing additional information for clarification.

\subsection{Data Organization Techniques}

Proper data organization techniques increase the credibility of the study [47]. After I compared the transcribed data with my interview notes, I commenced the data cleanup and data organization process. I organized the data in the following ways: 1) member checking the transcribed interview, 2) maintained a reflective journal to note my thoughts, assumptions, and experiences during the 
research process, 3) entered the raw data into NVivo12 ${ }^{\mathrm{Tm}}$, and 4) reviewed my notes against the interview questions. Bengtsson (2016) [48] stated that data organization is a vital component of a credible qualitative research study. Therefore, I used the following organizational tools: Mendeley, Microsoft Word, and Microsoft Excel for this study. I compiled the participants' responses from the interview questions, audio recording, and interview notes, and saved the audio files by the participant number to maintain confidentiality. SB1 for the owner from the first coffee shop, SB2 for the owner from the second coffee shop and so on.

\subsection{Date Analysis}

I used the 8 Ps of marketing mix in exploring the marketing strategies of successful coffee shop owners in Arkansas. The 8Ps of marketing mix is appropriate as coffee shop owners may leverage these strategies to remain in operation. My use of interview questions may answer the central question of the study. Additionally, case study researchers use methodological triangulation for the merging of multiple methods to reach a single conclusion that better supports that conclusion than using one of those methods [49]. The researcher use of triangulation of data sources strengthens the research study because it serves as an indication to the reader that the research is credible [50]. Triangulation is a strategy that is useful in the validation and reconciliation of data obtained after the application of different methods of information collection on the same subject of study [41]. An advantage of using a triangulation approach is that using multiple sources of data enhances the validity of the research [41].

In this qualitative multiple case study, following the guidance of Hussein (2015) [51], I used methodological triangulation by comparing the information I gathered from sources of data including the interviews, documents, and public records from Internet sources. Graue (2015) [52] stated that the researcher should be able to interpret and explain or analyze the data. Data analysis is one of the crucial steps in the qualitative research process [53]. The process of data analysis involves the categorizing, coding, analysis of the collected data, and the identification of significant themes [16].

When the interviews were complete, the responses were coded to protect privacy (coffee shop owners names were coded as SB1, SB2, SB3, SB4, and SB5), and NVivo ${ }^{\text {tw }}$ (QSR International) software was used to assist in identifying recurring words, phrases, subthemes, and universal themes. I used NVivo12 ${ }^{\mathrm{Tm}}$ because the software was more user-friendly than Atlas Ti data analysis software. Furthermore, I correlated the recurring themes with elements from the 8Ps conceptual framework. I imported the interview transcripts into NVivo $12^{\mathrm{mm}}$ software for data coding and identified, nodes, the critical subthemes, and themes aligned to my conceptual framework for data analysis. $\mathrm{NVivo}^{\mathrm{Tm}}$ is a data analysis software from the computer that qualitative researchers use for the organization, storage, and analysis of research data. Çayir and Saritas (2017) [54] stated that the use of computer software in data analysis allowed researchers to disseminate research 
result in a more explicable manner. Furthermore, Yin (2017) [16] proposed that researchers use data analysis to organize and categorize data into thematic codes.

Coding the data is the method the researcher utilizes to organize and prepare the data for the analysis [52]. Furthermore, coding the data enables the researcher to draw conclusions and present the findings of a phenomenon [52]. The coding, organizing, and categorizing data, and the researcher's awareness and participant observation are essential to the data analysis of the research topic [55].

\section{Reliability and Validity}

\subsection{Reliability}

To ensure reliability in qualitative research, the researcher needs to guard against personal bias [37]. In qualitative research, a researcher can use credible methods to increase the likelihood of consistent findings in future studies. Furthermore, Noble and Smith [37] posited that an independent researcher should arrive at similar or comparable research findings as the researcher. Leung (2015) [56] posited that reliability refers to the researcher's ability to replicate the research process and the research outcomes. One of the steps in ensuring the reliability of the interview as a research instrument is to obtain feedback on the interview protocol [57]. The researcher's goal is the ability to obtain the same results in a repeat of the study [58]. I ensured that I followed the steps suggested by Castillo-Montoya (2016) [57] in explicating the steps for ensuring the reliability of the interview protocol I used in the study. The interview protocol is steps included creating an audit trail, explicating 1) the purpose of the study, 2) participant selection, 3) data collection, 4) data analysis, 5) research findings, and 6) study conclusion.

To further ensure reliability in this study, I checked (verified) the accuracy of the interview responses using member checking. I ensure the alignment between the purpose of the study and the central research question. I ensured that I secured the elicited data in secure, electronic password-protected files on a USB drive that was stored in a locked file cabinet at my home. I stored the signed consent forms and other electronic files on my password-protected computer and backed up on a password-protected external hard drive. At the end of the 5 years, I will shred the paper documents and will erase the data from the external hard drive. I applied standard methodical approaches to achieve reliability in qualitative research consistent with a case study research method [16].

\subsection{Validity}

In qualitative research, researchers seek to ensure results are credible, transferable, and achieve confirmability in the research design and implementation [58]. Credibility is the assurance in the conclusion of the research findings which address the findings from the viewpoint of the participants, transferability refers to the applicability of the findings in other settings by adhering to 
data collection, data saturation, and analysis techniques for the case study design, and confirmability is the extent to which the participants shape the findings of the study [47].

Confirmability in qualitative study confirms that the research data is the participant's narrative and is free from the researcher's personal bias [51]. Validity in qualitative research as a critical component refers to the researcher's appropriateness of the data, the application of research methods, and the precise nature of the research findings [59]. Furthermore, to enhance a study's credibility, the researcher must ensure the research question, the research method, and research design all align with the desired outcome [56].

Cypress (2017) [60] indicated that in qualitative research, the validity of the findings of the study predicates on the researcher's due diligence with data collection during the research process. Researchers also indicated that additional strategies to achieve validity in the research study include peer review or debriefing, clarifying the researcher's bias, member checking, external audits, and triangulation [58]. Therefore, I applied methodological triangulation in the study by incorporating interviews, data from publicly available information on the website and social media networks of the coffee shop to ensure validity as recommended by Marshall and Rossman (2016) [14].

To achieve data saturation, the researcher must interview multiple study participants using the same set of questions [41]. Therefore, I asked the same set of questions to all the five coffee shop owners. I also collected data from SB websites and SB social media platforms. I collected data from five SBs using semistructured interviews until I reached the point of saturation. Fusch and Ness [41] stated that a researcher reaches data saturation when there are no new data or new codes, and no new themes. Furthermore, I documented the data collection instructions to ensure appropriate audit trail and asked the study participants to confirm their responses during the interview and the member-checking phase.

\section{Findings}

The overarching research question of my study was: What marketing strategies do some coffee shop owners use to sustain business operations during the first 5 years of operation? Based on the methodological triangulation of the data sources collected, eight emergent themes identified from the analysis of data collected through face-to-face interviews. A response was considered a theme if it was part of the response of at least three SBs. In the following subsections, I describe the study participants, the eight themes. In addition, I described how the participants answered the eleven interview questions. The data collected assisted in answering the research question, and the support of selecting the 8Ps of marketing mix as the conceptual framework for this study research.

Eight themes emerged from the analysis of data collected through face-to-face interviews. The themes were 1) business operations, 2) community engagement, 3) premium products, 4) use of social media for marketing, promotion, and 
branding, 5) competitive pricing, 6) location, 7) customer service and personalization, and 8) points of marketing differentiation. One significant finding was the lack of threat to coffee shop business by national brands. Coffee shop owners can successfully sustain business operations despite the threat of new entrants. The findings showed marketing strategies that the coffee shop owners used to sustain their operation to provide preferred customer service, increase sales, and differentiate the coffee shop from competitors.

\subsection{Themes}

Through semistructured interviews, social media platforms, and other publicly available data, I gained an in-depth understanding of the marketing strategies of coffee shop owners. The following is an analysis of the themes.

\section{Theme 1: Business operations}

One hundred percent of participants identified the need for longevity in the ownership of the business and active participation in the day-to-day operations of the business. Lude and Prügl (2018) [61] opined that consumers perceived brands that show their family association as more authentic than brands that do not. The subthemes that emerged during data analysis were the following: 1) longevity in the ownership of the coffee shop and 2) owners' family business structure and active participation in the day-to-day operations of the coffee shop. Theme 1-Business Operations Evidentiary Statements presented in Table 1.

In this business operations theme, specifically, the longevity in the ownership of the business, three out of five SBs $(60 \%)$ had engaged in business for more than 20 years. One had been in business for longer than 5 years, but less than 10 years and one had been in business for more than 10 years. In my research, an SB stated: "We are a family business and do not have an excess of employees who are not vested in the business" (personal communication, February 25, 2019).

Table 1. Business operations.

\section{SB Comment}

SB1 I have been in business for more than 20 years. A lot of the customers are our neighbors and friends. Actively engaged in day-to-day operations.

SB2 Actively engage-we are actively involved in the day-to-day operations of the coffee shop, including the hiring, baking, and brand promotion.

SB3 We worked to improve an existing business, in terms of the product, marketing and pricing of the coffee to ensure the best price available anywhere in the region.

SB4 Robust interaction-we are focused on our four walls, but I, I know every business owner on this street, every single one, I know them personally, I meet with them monthly, we have meetings here or the meetings at their place. We talk about strategies. We share ideas, and we share distributors. The success in our business operation is networking with other coffee shop owners, interacting with the community, customers, and frontline employees.

SB5 I own this business with one of my adult children. You know a coffee house is no different from any other business out there. I am responsible for hiring, and he is responsible for managing the frontline employees. 
Data collected from the SBs in my research indicated that in all cases, the SBs were active participants in the operations of the coffee shop. The owners engaged in the decision making regarding the brand alongside their adult children or spouse. SB2 and SB3 run the coffee shop with their spouses (personal communication, February 24, 2019; personal communication, February 25, 2019). SB1 and SB5 run the coffee shop location with the owner's adult children (personal communication, February 23, 2019; personal communication, February 27, 2019). One of the SBs conveyed that his job as the owner of the coffee shop was to oversee the direction of the staff in the initiatives that they are doing (personal communication, February 27, 2019).

\section{Theme 2: Community Involvement and Engagement}

Data collected from all five SBs indicated that four out of five SBs (80\%) all but one SB (20\%) were actively engaged and involved in the community. With community involvement and engagement initiatives, SBs gain customer loyalty, credibility, and trust [32]. SB can participate in the development of the community in which they are located. SB1 (personal communication, February 23, 2019) informed that the coffee shop was actively engaged in the community to the extent that community organizations sought out coffee donations for their events. Theme 2-Community Involvement and Engagement Evidentiary Statements are present in Table 2.

Most of the owners spent considerable time within the community. One of coffee shop owner sponsors a lot of charitable causes within the community,

Table 2. Community involvement and engagement.

\section{SB Comment}

SB1 I am known in the community as the coffee guy. I created the coffee shop because I was obsessed with the idea of creating a community space. I wanted to create a community space where everybody would be welcomed. Coffee shops or places can become community spaces.

SB2 Community-we care about the community. That is why we opened our coffee shop here in the community where we live. There is a need for communal experience, the place where people can gather. The $3^{\text {rd }}$ place after home and work. It is just never personally made sense to us to open in another town like a second location or wherever in another town because we do not know that community. We want to serve the people we see every day. Then you know what they are going through. We know their kids. We want to be part of the community, not just move people through like a number.

SB3 Not a community meeting place, even though the coffee shop is socially active during the mornings, we are primarily concerned with providing a product that people will appreciate.

SB4 Community immersion-what has been a strategy for us is to immerse ourselves into the community. Those are all things that are part of our mission. I believe that you must invest in your community and be concerned about what happens in your immediate neighborhood that goes beyond the four walls of the coffee shop.

SB5 We are all wrapped around an environment, that is warm and cozy, and community friendly. We are huge into the community and participate in various civic functions, charity organizations, entertainment and poetry nights, and Bible studies. I am not in the coffee shop a lot. I am in the community a lot. Moreover, I think that is what is cool about this shop is that we are an all-inclusive place and welcome the community into our shop. 
which align with the mission of the coffee shop owner, helping children, helping families, helping women, helping those who are transitioning, whether it be out of prison or poverty. The SBs conveyed that community involvement is a crucial ingredient to the success of the coffee shops.

\section{Theme 3: Premium Products}

Five out of five SBs identified the importance of having a premium product that rivals that of the national brands. Consistent with the findings of De Sá, de Paiva, Souki, and Moura (2017) [31] the most essential coffee product features included taste flavor, roasting point, and brew methods. Zhang et al. (2019) [31] found that the rich taste of coffee was most notable for customer satisfaction. Theme 3-Premium Products Evidentiary Statements are present in Table 3.

Although all the SB identified the threat of a new entrant, especially a national brand, they conveyed that the quality of their coffee products was better than the national brands coupled with their community immersion and engagement. The responses of the SBs reaffirm the statement of Hargis and Bradley (2011) [62] on the importance of creating unique products and services to build a competitive advantage.

\section{Theme 4: Use of Social Media for Marketing, Promotion, and Branding}

To grow a business and sustain business operations, a small business owner must attract foot traffic into the establishment. Popescu (2018) [63] opined that in other to grow revenue, a company engages with current and potential customers in a transactional manner. Five out of five SBs conveyed that their primary medium of advertising was word-of-mouth advertising. Business owners use word-of-mouth as a person-to-person communication tool to communicate information about a brand, product, or service [64]. Coffee shops rely a lot on

Table 3. Premium products.

\section{SB Comment}

SB1 We roast our own coffee beans and make every product we serve from scratch. We have always had fresh baked cookies and other products that complemented the coffee.

SB2 Quality products-a lot of people for convenience matters over quality, patronize national brand but I can say all our products are better than the national brands. We also have artisan bakery products. We make all the syrups for all the coffees. I have a baking assistant. I bake all our pastries, scones, cookies, and muffins. We make all the bagels by hand. We make all the sandwiches, make everything. Our goal is to be self-sufficient eventually.

SB3 We pride ourselves in producing the best coffee products. We have had several opportunities to put in satellite coffee shop locations, but we turned them down because we do not want to spread ourselves too thin to the extent that it damages the quality of our products. Because if you damage your reputation in a business like this, it is hard to get it back.

SB4 We only use premium coffee beans and roast our beans in-house. We provide made from scratch, artisan products. Using time tested recipes, we have maintained the same quality in the taste of our products for decades. Our products are categorized by category, namely, breakfast, lunch, and cakes.

SB5 We market a high-end premium product. We have a professional roaster in-house and create our single origin coffee and specialty coffee blends. For us, we cannot afford to devalue our product which explains why we give our product a premium price tag. 
word-of-mouth marketing because of their engagement in the community (SB1, personal communication, February 23, 2019; SB4, personal communication, February 27, 2019; SB5, personal communication, February 27, 2019). All the SBs interviewed also have a Facebook page as a medium to engage with customers and to expose their brand.

The ability to utilize information technology in marketing is a key ingredient to the success of a small business. SBs often lack information technology skills and expertise [6]. SB4 conveyed that one of the critical challenges the coffee shop faced was transitioning from sole reliance on word-of-mouth marketing to social media marketing and promotion of the brand (personal communication, February 27, 2019). Theme 4-Use of Different Media for Marketing, Promotion, and Branding Evidentiary Statements are present in Table 4.

Popescu (2018) [63] affirmed that improved online reputation leads to a company's higher visibility on search engines. Kujur and Singh (2016) [65] posited that the business owners must develop a plan for their online social media presence and social media platform preference. SB2 and SB4 conveyed that they have received greater engagement from Instagram (personal communication, February 24, 2019; personal communication, February 27, 2019). SB2 and SB4 also connect their Instagram account to their Facebook page posting simultaneously to both platforms for maximum exposure (personal communication, February 24, 2019; personal communication, February 27, 2019). Popescu (2018) [63] opined that traditional ways of finding local business were becoming obsolete in favor of newer forms of marketing. All the SBs I interviewed have Facebook pages. Cultivating and maintaining online customer relationships helped to maintain ongoing interactions between the coffee shop and the customers even after leaving the coffee shop [66]. The SB1 conveyed that one of their locations

Table 4. Use of social media for marketing, promotion, and branding.

SB Comment
SB1 We use word-of-mouth advertising and donations for marketing, promotion and exposing
our brand to the community. We have built trust, loyalty, and credibility on this community
over the years. We also use social media Instagram and Facebook to reach the younger
target market.
We engage in social media to engage the community. We are deliberate about hiring
creative people who can also promote the brand via social media.
In addition to Facebook, we also engage in listing services such as Yelp to promote the
brand and the coffee shop and regularly receive high reviews. People come into our business
based on what they see online.
We use mobile resources like print media and a bit of radio. This may sound old-fashioned
but that this how we have grown our brand in the past. We are transitioning now into more
of a social media presence through Facebook and Instagram. We have recently enlisted the
help of an Instagram expert. Our social media presence has made an impact on our sales.
We have recently revamped his website and optimized it to achieve search engine
optimization (SEO). This SB also hired a dedicated marketing person to handle social media
accounts of the coffee shop. We also plan to promote and sell our products through
subscription sales.


received awards for the best Instagram photos (personal communication, February 23, 2019).

\section{Theme 5: Competitive Pricing Strategy}

A business owner may use an assortment of pricing strategies when selling a product or service. Pricing strategy is a business owner's ability to integrate resources to control the best price for maximum profit and maintain competitive advantage [41]. One of the questions I asked the SBs was the pricing strategy that they used in the first 5 years in business operation. Theme 5-Competitive Pricing Strategy Evidentiary Statements are present in Table 5.

All the SBs recommended competitive pricing strategy to gain new customers and retain existing ones. The responses of the SBs affirm the statement of [67]. Rajasekaran (2015) that a business owner must pay attention to pricing to achieve a competitive advantage in the coffee shop business and to grow the customer base. Additional effective marketing strategies that SBs used to remain in business for more than 5 years included location, customer service, and personalization, and points of marketing differentiation.

\section{Theme 6: Location}

The location of each coffee shop indicated a direct connection between the SBs' desire to create a community space and sustain business operations as a coffee shop owner. One hundred percent of the SBs conveyed that the location was an essential factor in building and sustaining a successful coffee shop that can withstand the threats of new entrants into the coffee business. I observed that all the SBs were in business districts or downtown areas. One of the SBs (20\%) had the added advantage of being located close to a University. Success or

Table 5. Competitive pricing strategy.

\section{SB Comment}

SB1 We conduct marketing research to determine the coffee price. We are not cheap but not overly pricey. We have never been big on pricing but the quality of the coffee and the customer experience. We have had a good corner in the area coffee market for years.

SB2 Competitive pricing strategy - we have tried not to be too high or too low, but to maintain fair but competitive pricing that our customers are willing to pay. In some instances, we are 50 -70 cents cheaper than the national brands. Our customers appreciate the quality of our product. We also roast our coffee beans onsite.

SB3 Sustaining model-ur pricing strategy has been and continues to be to produce the best coffee available at the best price. We have low overhead as we are family-owned and do not have an excess of part-time employees. We focus on pricing the products in a manner that allows us to retain our loyal customer base.

SB4 So, our process is very similar. It is the same as it has been in years, so that part never really changes. What impacts our pricing strategy is food costs. We benchmark with other coffee shop owners to maintain a competitive pricing strategy. In the coffee shop business, you are not going to make much money unless you change your price point or sell more units.

SB5 Premium product pricing-I could sell my coffee for less, but then I have devalued my product. I have a premium product, and we give it a premium price tag. We are a coffee by choice destination. If you are running five, seven, $10 \%$ on earnings before interest, tax, depreciation, and amortization (EBITDA), you are doing okay. 
failure was predicated on selecting the right location for any business [44]. Coffee shop owners are strategic about the location of coffee shops [68]. In addition to the physical location, the SBs also conveyed their decision for the interior décor of the coffee shops. Theme 6-Location Evidentiary Statements are present in Table 6.

In this theme, all the SBs indicated that the location of their coffee shop was a key indicator of profits. SB5 conveyed that most of his coffee sales were derived from the surrounding neighborhoods, commuters, and the people in the community (personal communication, February 27, 2019). For coffee shop owners to succeed in business operation beyond the first 5 years, SB4 conveyed that the best location might be determined by examining the community dynamics and ample parking (personal communication, February 27, 2019). By benchmarking their geographical location to those competitors, coffee shop owners may uncover the strengths and weakness of their coffee shops and use the insight gathered to make operational decisions [63].

\section{Theme 7: Customer Service and Personalization}

Five out of five SBs conveyed that in a coffee shop business, superior customer service and personalization of services were non-negotiables. All the SBs indicated that to increase the customer base or foot traffic in a service-oriented business, the owner must create a customer-friendly environment. SB2 moved the location of their coffee shop to provide a place where they could serve a more diverse clientele. Theme 7-Customer Service and Personalization Evidentiary Statements are present in Table 7.

Two of the SBs (40\%) conveyed that they were taking steps to evolve the service. SB4 indicated that he could have tremendous improvement in how the coffee shop connects with customers (personal communication, February 27, 2019). For example, SB4 does not currently retain customer data for ongoing engagement.

Theme 8: Points of Marketing Differentiation

Porter (1980) [69] recommended successful business owners need to differentiate

Table 6. Location.

\section{SB Comment}

SB1 High traffic volume, close to a business district. In addition to the location of the coffee shop, we wanted the internal location of each of our coffee shops to be different. We did not want our location to look like the national chains. We serve the same drinks at each location, but the ambiance is different.

SB2 Downtown location. We love old things and staying in downtown was important to us. Our decision to stay downtown was mainly because downtown is where the heart is. Third place (home, work, and coffee shop).

SB3 Right location. There was not much else this location could be used for. The location was perfect for a small drive-through type of business.

SB4 High traffic volume, off the highway and in a business district.

SB5 We are a destination, but we wanted a community space to have an intimate coffee house. 
themselves from their competitors in an atmosphere of aggressive competition. To sustain business operations beyond the first 5 years, 100\% of the SBs agreed to have points of marketing differentiation that transcended a great product, price, or location. The SBs conveyed that they needed points of marketing differentiation that provided a competitive advantage against other coffee shop owners. Lude and Prügl (2018) [61] recommended that managers of family-owned businesses leverage the inherent differentiation potential of being a family-owned business in their marketing and branding strategies. The SBs indicated that they achieved marketing differentiation from other coffee shop owners and the large chain coffee shops through their connection to the community and exceptional customer service. The SBs stressed the importance of having a close connection to the customers. Theme 8-Points of Marketing Differentiation Evidentiary Statements are present in Table 8.

Zeriti, Robson, Spyropoulou, and Leonidou (2014) [70] affirmed that effective marketing strategies contributed to attracting customers to buy the products and

Table 7. Customer service and personalization.

\section{SB Comment}

SB1 A culture of customer service-we are deliberate in the way we provide customer service and personalization. We created a coffee shop where everyone would be welcomed and served by a diverse and eclectic front-line staff.

SB2 Familiar faces-as owners, we are behind the counter talking to people. People like how we serve them. We do not insist that people buy anything when they come into our coffee shop. Paying and non-paying customers can sit in the coffee shop and enjoy free Wi-Fi for an extended period.

SB3 We pride ourselves in providing exceptional customer service. We are not a traditional coffee house. We do not have any frills, but our customer base is loyal. Enhanced customer retention strategy.

SB4 Relational, not transactional-we never want to be transactional. I want it to be about the experience someone has and how well they connect with us here.

SB5 We have created a better customer service experience, better bean selection, and revamped the menu. I am learning how to communicate better with and manage millennial baristas.

Table 8. Points of marketing differentiation.

\section{SB Comment}

SB1 We market our brand through clothing and apparel and market to our local community in a manner that shows that we are genuine and have a connection to the community that cannot be replicated by national chains.

SB2 We are laidback in our approach to marketing. This approach is innovative, and we are incorporate in our marketing of niche products and brand apparel.

SB3 We have maintained our drive-through and a drive-up window. $80 \%$ of our business is at the drive-up window.

SB4 Willing to accept mistakes-when we make mistakes, we own it and make it right for the customer. If it is a significant error, we will not charge the customer.

SB5 Create a quality product-provide the best selection of roasted beans with a single origin and signature blends and marketing them to high-end clientele. 
services of a business. In support of Zeriti et al. [70], five out of five SBs conveyed that quality, consistency, and value were critical points of marketing differentiation in a service business for example, a coffee shop. One of the SBs indicated that creating points of marketing differentiation as an effective marketing strategy means as a coffee shop owner, you need to develop your niche. In addition to selling coffee products, the SB would need to market complementary artisan products. Another SB conveyed that he was in the process of creating a line of grab-and-go products marketed at the busy professionals who just want to eat on the go. Another point of marketing differentiation one SB shared was offering open pour coffee. Open pour coffee looks old fashioned but had become popular with regular customers. SB5 indicated that he tries to affiliate and collaborate as a coffee shop owner with mid-to-upscale restaurants and create private label blends exclusively sold to those restaurants and bakery shops (personal communication, February 27, 2019).

\subsection{Other Relevant Finding: Key Challenges}

Alford and Page (2015) [4] posited that small business owners lack knowledge of business administration including marketing strategies and technology to survive in small business. SBs have operational challenges during the initial stage of the business [5] [6]. In response to question number two, all the SBs conveyed that the most significant challenge was trying to learn the ropes of business operation while implementing the coffee shop owner's marketing strategy. One of the SBs conveyed the following:

One of the challenges that we faced in implementing our marketing strategy was that there was not any downtown culture or coffee culture at all. Downtown was a forgotten part of town. So, our challenge was getting people to come down here when there was not much to come downtown to do.

Another SB conveyed that the biggest challenge in implementing their marketing strategy was having a basic understanding on how to use the social media platforms and combining social media marketing with the traditional word-of-mouth marketing that he was accustomed to. SB5 indicated that the key challenge in implementing the marketing strategy for the coffee shop was creating an awareness of the coffee shop after there was a change in ownership (personal communication, February 27, 2019).

Table 9 is a depiction of how I supported the 8Ps of marketing mix as the conceptual framework for this research.

\subsection{Applications to Professional Practice}

The findings of this study may assist coffee shop owners in Arkansas in determining the best marketing strategies. The findings of the study could contribute significantly to professional business practice by 1) providing a marketing guide for operating a coffee shop and 2) evaluating current and future marketing strategies to enhance their competitive advantage. In the study, the SBs indicated 
Table 9. Mapping interview questions to the conceptual framework.

\begin{tabular}{|c|c|c|c|}
\hline Interview & SB Question & Conceptual & Rationale/Coded theme \\
\hline Question & & Framework & \\
\hline Number & & Component & \\
\hline
\end{tabular}

1. What marketing strategies have you used to sustain Processes, people, business operations during the first 5 years of promotion operation?

2. What were the key challenges you had in Processes, physical implementing your marketing strategies during the evidence, promotion first 5 years of operation?

3. How did you address the critical challenges to your People marketing strategies during the first 5 years of operations?

4. What marketing strategies helped you to increase Promotion your customer base during the first 5 years of operation?

5. How did you establish your pricing strategy compared to the pricing of your competitors during the first 5 years of operation?

6. contribute to increasing your customer base during the first 5 years of operation?

What media were most effective at creating more foot traffic into your coffee shop during the first 5 years of operation?

Price

(1)

Promotion

What were the main points of differentiation that you emphasized in your promotional messages during the first 5 years of operation?

9. How did you merchandise your products to be more appealing to customers during the first 5 years of operation?

(1)

(1)
Personalization, product, Premium proud, a brand associated with the promotion, people community., quality, consistency, and value, employees make the difference

Promotion,
personalization, pricing

Personalization coffee shop during the first 5 years of operation do (Quality) you recall?

11. What additional information can you provide regarding marketing strategies you used to sustain business operations during the first 5 years?
Personalization

(Productivity), people, promotion
Business operations - active engagement in the running of all aspects the business, be all in, be true to self, perseverance, take care of your staff

Learning the ropes of the business, using a hybrid of word-of-mouth and social media to implement marketing strategies

Hire people who are smarter than you, network with other coffee shop owners, relational first, then transactional, enhanced personal communication skills

The coffee donation, inviting interior, accepting of all diverse patrons, word-of-mouth, community outreach

Food and coffee bean prices, benchmark with other coffee shop owners, fair but sustainable pricing

Location is crucial, community involvement and engagement, coffee shop ambiance is eclectic

Initially, word-of-mouth, transitioned to social media (Facebook and Instagram), online listing services (Yelp) and other form of electronic media (Radio)

Decide who your target market is and do not devalue your brand. Offer multiple channels of trade and customization-retail, online, wholesale

Make everyone feel welcome. Have exceptional and well-trained frontline employees. Own your mistakes.

Take care of customers, have a niche and artisan products, leading by example, "non-corporate", get to know people, build an online presence

that their involvement and engagement in the community and the adoption of new media were crucial aspects of the sustenance of their coffee shops and an increase in the customer base in a competitive coffee shop environment.

The SBs identified providing premium coffee and artisan products brought in regular and loyal customers into the shop. The findings of this study apply to coffee shops in several ways including community engagement, social media adoption, location, and front-line business operations. Social media is a crucial factor in minimizing marketing challenges [71]. As more people use third places for example, coffee shops as a public gathering place outside of home and work (Van der Merwe \& Maree, 2016) [72], the owners' active community engage- 
ment contributes to the strength of a community [49].

By conducting this research study, I add to the existing body of knowledge regarding marketing strategies of coffee shops. Emergent themes of the study included community involvement and online social media engagement. The results of this study contribute to business practice by providing information to individuals who are considering opening a service business and specifically to coffee shop owners who want to improve the marketing strategies of coffee shops. Mukherjee and Shivani (2016) [19] stated that the consideration of the traditional marketing mix elements of product, price, place, and promotion as well as the newer elements of participants, physical evidence, and the process might assist a business owner in achieving the marketing objectives in services. The 8Ps of marketing mix for coffee shop owners is a visual representation of the components of marketing mix and designed to enhance a coffee shop owners' marketing mix. The model includes 8 themes that emerged from my study.

According to Goldsmith (1999) [20], the 8Ps of marketing mix enhances the survivability of a service-oriented business. In my study, I found that the owners of coffee shops executed marketing strategies determined the community in which they were located.

\subsection{Implications for Social Change}

The poor execution of marketing strategies and technology is one of the factors contributing to small business failures [4] [5]. By implementing more marketing strategies, coffee shop owners could sustain the business operation. Stephan, Patterson, Kelly, and Mair (2016) [73] posited that social change requires an intentional commitment to societal transformation. Positive social change requires a commitment to contribute to society in a substantial and positive manner.

Positive social change may result in a reduction in the number of coffee shop failures, thus improving employees' worth and dignity, and reducing the unemployment rates, which can result in building stronger communities through gainful employment. The findings of this study identified multiple ways for owners of coffee shops to contribute to social change in their community by 1 ) sustaining the operation of coffee shops in local communities, 2) contributing to new job creation, and 3) contributing to regional economic growth. By adopting the recommendations for further action, owners of coffee shops may avoid the downside of coffee shop failure by using the recommendations as a blueprint for maximizing marketing strategies, increasing their customer base, and enhancing competitive advantage against competitors.

\subsection{Recommendations for Action}

Having marketing strategies is vital to the sustenance of coffee shops. Nguyen et al. (2015) [6] opined that adopting effective marketing strategies is pertinent to the sustenance of coffee shops. The findings of this study are not only significant for existing coffee shop owners but also valuable for potential coffee shop own- 
ers. Using the strategies identified in this study may 1 ) reduce the challenges coffee shop owners face in the business operations; 2) enhance owners' ability to maximize their current marketing strategies, and 3) expand owners' capacity to integrate new marketing strategies to create points of differentiation which may result in a competitive advantage.

Some coffee shop owners lack marketing strategies for sustaining business operations beyond the first 5 years. The study findings indicate that coffee shop owners can use a combination of marketing strategies to sustain their businesses. I recommend coffee shop owners should engage in their communities, adopt social media, offer premium and artisan products, and provide exceptional customer service for sustaining their business. Lude and Prügl (2018) [61] also recommended that the managers of family firms should include statements about their family background in their branding strategy for differentiation purposes. The family background could depict in the form of a tagline on the brand logo. For example, the coffee shop owner could include the tagline: a family tradition since 1972 .

\subsection{Recommendations for Further Research}

I conducted a qualitative multiple case study to explore what strategies some coffee shop owners use to sustain business operations beyond the first 5 years. I explored and uncovered common themes that emerged from the participant face-to-face interviews and social media networks. I selected the qualitative research method so I could better explore and understand the thought processes of my study subjects. The limitations affecting this multiple case study are the choice of an exploratory multiple case study of five small business owners of coffee shops from Arkansas may not yield enough data to answer the research question and may not be representative of the population of coffee shop owners in the United States or other countries.

The first recommendation for the future study is how to overcome the challenge of coffee shop owner face in continuing to engage and remain relevant in the community as changes occur in the community. Yuen and Johnson (2016) [74] opined that third places (coffee shops) were gathering places that contributed to the strength of a community. Coffee shop owners could help foster a sense of community by incorporating local concepts in the interior design, décor, and having exceptional front-line service.

The second recommendation for further study is how to overcome the challenges of social media adoption. Ogbuji and Papazafeiropoulou (2016) [71] posited that in the dynamic marketplace, the small business owner might face marketing challenges without a proactive social media adoption. The SBs I interviewed conveyed that they needed to leverage the possibilities of social media in promoting their coffee shops. Through social media and social location marketing, customers can share their experiences and check in with others [68]. Instagram is based on visual content for example, posting of pictures, and Face- 
book has the capability for the customer to check into the coffee shop Check-ins show up in the feeds of that customer's Facebook friends, creating opportunities for people to see the business on Facebook. Furthermore, Chua, Deans, and Parker (2015) [75] posited that blogs are a tool that business owners use by business owners for branding, managing reputation, and promoting their online presence. Coffee shop owners can use blogging to drive engagement on social media.

The third recommendation for further study is how to overcome the challenge of improving front-line engagement with customers and consistently providing exceptional customer service. Increasing levels of customer service result in customer satisfaction and may produce more profits [20]. Stock et al. (2016) [76] suggested that frontline employees may help the customer by making product recommendations, recognizing customers' preferences. Coffee shop owners must concentrate on efforts to improve consistency and service quality.

Coffee shop owners interviewed care about quality, consistency, and value. Customers usually appreciate the quality of coffee based on their taste and presentation [48]. Prayag et al. (2016) highlighted the importance of implementing service quality and service delivery components influencing customer service. A study conducted outside of Arkansas may determine whether the findings of this study are peculiar to Arkansas only or if the findings are transferable to a broader geographical area. Furthermore, researchers should employ a different qualitative research design, for example, phenomenology or ethnography or a quantitative research design such as experimental to explore further marketing strategies for the continued sustenance of coffee shop operations.

\section{Conclusions}

The purpose of this qualitative multiple case study was to explore what strategies coffee shop owners in Arkansas state use to sustain business operations beyond the first 5 years.

Using open-ended questions, I conducted semistructured interviews with 5 coffee shop owners to collect data to answer the research question. Data were derived from an in-depth analysis of 11 semistructured interview questions answered by 5 successful coffee shop owners, social media platforms, other publicly available data, and member checking. The data reached saturation when the coffee shop owners did not provide any new information, and no new themes emerged [41]. I used NVivo12 $2^{\mathrm{m}}$, computer-assisted qualitative data analysis software to organize and analyze data. Eight themes emerged from the thematic analysis of data to explore the marketing strategies coffee shop owners in Arkansas use to sustain business operations beyond the first 5 years. The themes were 1) business operations, 2) community engagement, 3) premium products, 4) use of social media for marketing, promotion, and branding, 5) competitive pricing, 6) location, 7) customer service and personalization, and 8) points of marketing differentiation. 
The marketing strategies identified in the findings provided solutions that owners of coffee shop owners and their stakeholders can use to grow and sustain their business. One significant finding was the lack of threat to coffee shop business by national brands. Coffee shop owners can successfully sustain business operations despite the threat of new entrants. The findings showed marketing strategies that the coffee shop owners used to sustain their operation to provide preferred customer service, increase sales, and differentiate the coffee shop from competitors. Using the 8Ps of marketing mix as a lens for this study, which involved coffee shop owners; this study may fill a gap in the literature. The study findings included the importance of community involvement and engagement, location, the adoption of social media, and the benefits of using the appropriate mix of marketing strategies to sustain coffee shop operations beyond the first 5 years.

\section{Conflicts of Interest}

The author declares no conflicts of interest regarding the publication of this paper.

\section{References}

[1] Hyder, S. and Lussier, R.N. (2016) Why Businesses Succeed or Fail: A Study on Small Businesses in Pakistan. Journal of Entrepreneurship in Emerging Economies, 8, 82-100. https://doi.org/10.1108/JEEE-03-2015-0020

[2] Fang He, V., Sirén, C., Singh, S., Solomon, G. and von Krogh, G. (2018) Keep Calm and Carry on: Emotion Regulation in Entrepreneurs' Learning from Failure. Entrepreneurship Theory and Practice, 2018, 12273. https://doi.org/10.1111/etap.12273

[3] Hsu, D.K., Wiklund, J. and Cotton, R.D. (2017) Success, Failure, and Entrepreneurial Reentry: An Experimental Assessment of the Veracity of Self-Efficacy and Prospect Theory. Entrepreneurship Theory and Practice, 41, 19-47. https://doi.org/10.1111/etap.12166

[4] Alford, P. and Page, S.J. (2015) Marketing Technology for Adoption by Small Business. The Service Industries Journal, 35, 655-669. https://doi.org/10.1080/02642069.2015.1062884

[5] Lotfizadeh, F. and Shamsi, N. (2015) Evaluating the Factors Affecting SMEs Performance in Iran. International Journal of Management, Accounting and Economics, 2, 254-264. https://www.ijmae.com

[6] Nguyen, T.H., Newby, M. and Macaulay, M.J. (2015) Information Technology Adoption in Small Business: Confirmation of a Proposed Framework. Journal of Small Business Management, 53, 207-227. https://doi.org/10.1111/jsbm.12058

[7] Small Business Administration (SBA) Office of Advocacy (2017) Arkansas Small Business Profile, 2017. https://www.sba.gov/sites/default/files/advocacy/Arkansas_1.pdf

[8] United States Census Bureau (2016) 2014 SUSB Annual Data Tables by Establishment Industry. https://www.census.gov/data/tables/2014/econ/susb/2014-susb-annual.html

[9] U.S. Census Bureau (2017) 2017 NAICS Definition-722515 Snack and Nonalcoholic Beverage Bars. https://www.census.gov/cgi-bin/sssd/naics/naicsrch

[10] Knoema (2016) Number of Starbucks Stores Globally, 1992-2016. 
https://knoema.com/kchdsge/number-of-starbucks-stores-

[11] Resnick, S.M., Cheng, R., Simpson, M. and Lourenço, F. (2016) Marketing in SMEs: a “4Ps" Self-Branding Model. International Journal of Entrepreneurial Behavior \& Research, 22, 155-174. https://doi.org/10.1108/IJEBR-07-2014-0139

[12] Muhammad, A. and Lee, S.P. (2015) Factors of Customer's Preference of Visiting Coffee Shop in South Korea. International Journal of Sciences. Basic and Applied Research, 24, 252-265. http://gssrr.org/index.php?journal=JournalOfBasicAndApplied\&page=index

[13] Bureau of Labor Statistics (2016) Survival of Private Sector Establishments by Opening Year.

http://www.bls.gov/bdm/us_age_naics_72_table7.txthttp://www.bls.gov/bdm/us_ag e_naics_72_table7.txt

[14] Marshall, C. and Rossman, G.B. (2016) Designing Qualitative Research. 6th Edition, Sage, Thousand Oaks, CA.

[15] Arbussa, A., Bikfalvi, A. and Marquès, P. (2017) Strategic Agility-Driven Business Model Renewal: The Case of an SME. Management Decision, 55, 271-293.

https://doi.org/10.1108/MD-05-2016-0355

[16] Yin, R.K. (2017) Case Study Research: Design and Methods. 6th Edition, Sage, Thousand Oaks, CA.

[17] Bloomberg, L.D. and Volpe, M. (2018) Completing Your Qualitative Dissertation: A Road Map from Beginning to End. 4th Edition, Sage, Los Angeles, CA.

[18] Snelson, C.L. (2016) Qualitative and Mixed Methods Social Media Research: A Review of the Literature. International Journal of Qualitative Methods, 15, 1-15. https://doi.org/10.1177/1609406915624574

[19] Mukherjee, S. and Shivani, S. (2016) Marketing Mix Influence on Service Brand Equity and Its Dimensions. Vision: The Journal of Business Perspective, 20, 9-23. https://doi.org/10.1177/0972262916628936

[20] Goldsmith, R.E. (1999) The Personalised Marketplace: Beyond the 4Ps. Marketing Intelligence \& Planning, 17, 178-185. https://doi.org/10.1108/02634509910275917

[21] McCarthy, E.J. (1960) Basic Marketing. Richard D. Lewin, Chicago, IL.

[22] Booms, B.H. and Bitner, B.J. (1981) Marketing Strategies and Organization Structures for Service Firms. In: Donnelly, J.H. and George, W.R., Eds., Marketing of services, American Marketing Association, Chicago, IL, 47-51.

[23] Pomering, A. (2017) Marketing for Sustainability: Extending the Conceptualisation of the Marketing Mix to Drive Value for Individuals and Society at Large. Australasian Marketing Journal, 25, 157-165. https://doi.org/10.1016/j.ausmj.2017.04.011

[24] Small Business Administration (SBA) (2018) What's New with Small Business? https:/www.sba.gov/sites/default/files/Whats-New-With-Small-Business-2018.pdf

[25] Guzman, J.B. and Lussier, R.N. (2015) Success Factors for Small Business in Guanajuato, Mexico. International Journal of Business and Social Science, 6, 1-7. http://ijbssnet.com/

[26] Memili, E., Fang, H., Chrisman, J. and Massis, A. (2015) The Impact of Small- and Medium-Sized Family Firms on Economic Growth. Small Business Economics, 45, 771-785. https://doi.org/10.1007/s11187-015-9670-0

[27] Borden, N.H. (1964) The Concept of the Marketing Mix. Journal of Advertising Research, 4, 2-7. http://www.jar.warc.com

[28] Culliton, J.W. (1948) The Management of Marketing Costs. Harvard University, Division of Research, Graduate School of Business Administration, Boston, MA 
[29] Mutandwa, E., Taremwa, N.K. and Tubanambazi, T. (2015) Determinants of Business Performance of Small and Medium-Sized Enterprise in Rwanda. Journal of Developmental Entrepreneurship, 20, 1-12. https://doi.org/10.1142/S1084946715500016

[30] Hidayanti, I., Herman, L.E. and Farida, N. (2018) Engaging Customers through Social Media to Improve Industrial Product Development: The Role of Customer Co-Creation Value. Journal of Relationship Marketing, 17, 17-28. https://doi.org/10.1080/15332667.2018.1440137

[31] Zhang, M., Kim, P.B. and Goodsir, W. (2019) Effects of Service Experience Attributes on Customer Attitudes and Behaviours: The Case of New Zealand Café Industry. Journal of Hospitality Marketing \& Management, 28, 28-50. https://doi.org/10.1080/19368623.2018.1493711

[32] Utami, T.I., Bayani, I. and Eprilisanti, A. (2018) Service Quality in Increasing the Loyalty of Coffee Consumers. International Journal of Recent Scientific Research, 9, 259-25987.

[33] Marek, P. (2014) A Critical Analysis of the Concept of Marketing Strategies for Small and Mid-Sized Companies. Economics, Management \& Financial Markets, 9, 255-261.

http://www.addletonacademicpublishers.com/economics-management-and-financi al-markets

[34] Park, J. and Park, M. (2016) Qualitative versus Quantitative Research Methods: Discovery or Justification? Journal of Marketing Thought, 3, 1-7.

[35] Dresch, A., Lacerda, D. and Cauchick Miguel, P. (2015) A Distinctive Analysis of Case Study, Action Research and Design Science Research. Rbgn-Revista Brasileira De Gestao De Negocios, 17, 1116-1133. https://doi.org/10.7819/rbgn.v17i56.2069

[36] Gaya, H.J. and Smith, E.E. (2016) Developing a Qualitative Single Case Study in the Strategic Management Realm: An Appropriate Research Design? International Journal of Business Management and Economic Research, 7, 529-538. http://www.ijbmer.com

[37] Noble, H. and Smith, J. (2015) Issues of Validity and Reliability in Qualitative Research. Evidence Based Nursing, 18, 34-35. https://doi.org/10.1136/eb-2015-102054

[38] Gentles, S.J., Charles, C., Ploeg, J. and McKibbon, K. (2015) Sampling in Qualitative Research: Insights from an Overview of the Methods Literature. The Qualitative Report, 20, 1772-1789. https://nsuworks.nova.edu/tqr/vol20/iss11/5

[39] Fletcher, D., Massis, A.D. and Nordqvist, M. (2016) Qualitative Research Practices and Family Business Scholarship: A Review and Future Research Agenda. Journal of Family Business Strategy, 7, 8-25. https://doi.org/10.1016/j.jfbs.2015.08.001

[40] Parveen, F., Jaafar, N.I. and Ainin, S. (2015) Reflections of Malaysian Social Media Managers. Telematics and Informatics, 32, 67-78. https://doi.org/10.1016/j.tele.2014.03.001

[41] Fusch, P.I. and Ness, L.R. (2015) Are We There Yet? Data Saturation in Qualitative Research. Qualitative Report, 20, 1408-1416. http://nsuworks.nova.edu/tqr/

[42] Clark, K.R. and Vealé, B.L. (2018) Strategies to Enhance Data Collection and Analysis in Qualitative Research. Radiologic Technology, 89, 482-485.

http://www.radiologictechnology.org

[43] Gudkova, S. (2017) Interviewing in Qualitative Research. In: Qualitative Methodologies in Organization Studies, Volume 2, Springer International Publishing, Berlin, 75-96. https://doi.org/10.1007/978-3-319-65442-3_4

[44] Parsa, H.G., van der Rest, J.I., Smith, S.R., Parsa, R.A. and Bujisic, M. (2015) Why 
Restaurants Fail? Part IV: The Relationship between Restaurant Failures and Demographic Factors. Cornell Hospitality Quarterly, 56, 80-90. https://doi.org/10.1177/1938965514551959

[45] Birt, L., Scott, S., Cavers, D., Campbell, C. and Walter, F. (2016) Member Checking: A Tool to Enhance Trustworthiness or Merely a Nod to Validation? Qualitative Health Research, 26, 1802-1811. https://doi.org/10.1177/1049732316654870

[46] Silverman, D. (2017) How Was It for You? The Interview Society and the Irresistible Rise of the (Poorly Analyzed) Interview. Qualitative Research, 17, 144-158. https://doi.org/10.1177/1468794116668231

[47] Sutton, J. and Austin, Z. (2015) Qualitative Research: Data Collection, Analysis, and Management. The Canadian Journal of Hospital Pharmacy, 68, 226-231. https://doi.org/10.4212/cjhp.v68i3.1456

[48] Bengtsson, M. (2016) How to Plan and Perform a Qualitative Study Using Content Analysis. NursingPlus Open, 2, 8-14. https://doi.org/10.1016/j.npls.2016.01.001

[49] Heesen, R., Bright, L.K. and Zucker, A. (2016) Vindicating Methodological Triangulation. In: Synthese, Springer, Netherlands, 1-15.

[50] Taylor, S.J., Bogdan, R. and DeVault, M. (2015) Introduction to Qualitative Research Methods: A Guidebook and Resource. 4th Edition, John Wiley \& Sons, London, UK.

[51] Hussein, A. (2015) The Use of Triangulation in Social Sciences Research: Can Qualitative and Quantitative Methods Be Combined? Journal of Comparative Social Work, 4, 1-12. http://journal.uia.no/index.php/JCSW https://doi.org/10.31265/jcsw.v4i1.48

[52] Graue, C. (2015) Qualitative Data Analysis. International Journal of Sales, Retailing and Marketing, 4, 5-14. http://www.ijsrm.com

[53] Mayer, I. (2015) Qualitative Research with a Focus on Qualitative Data Analysis. International Journal of Sales, Retailing and Marketing, 4, 57-67. http://ijsrm.com

[54] Çayir, M.Y. and Saritas, M.T. (2017) Computer Assisted Qualitative Data Analysis: A Descriptive Content Analysis. Necatibey Faculty of Education Electronic Journal of Science and Mathematics Education, 11, 518-544.

http://www.nef.balikesir.edu.tr/ dergi/

[55] Chowdhury, M.F. (2015) Coding, Sorting and Sifting of Qualitative Data Analysis: Debates and Discussion. Quality and Quantity, 49, 1135-1143. https://doi.org/10.1007/s11135-014-0039-2

[56] Leung, L. (2015) Validity, Reliability, and Generalizability in Qualitative Research. Journal of Family Medicine and Primary Care, 4, 324-327. https://doi.org/10.4103/2249-4863.161306

[57] Castillo-Montoya, M. (2016) Preparing for Interview Research: The Interview Protocol Refinement Framework. Qualitative Report, 21, 811-830. http://nsuworks.nova.edu/tqr/

[58] Morse, J.M. (2015) Critical Analysis of Strategies for Determining Rigor in Qualitative Inquiry. Qualitative Health Research, 25, 1212-1222. https://doi.org/10.1177/1049732315588501

[59] Abbaszadeh, M. and Abbaszadeh, M. (2016) Validity and Reliability in Qualitative Researches. Journal of Applied Sociology, 23, 19-34.

[60] Cypress, B.S. (2017) Rigor or Reliability and Validity in Qualitative Research. Dimensions of Critical Care Nursing, 36, 253-263.

https://doi.org/10.1097/DCC.0000000000000253 
[61] Lude, M. and Prügl, R. (2018) Why the Family Business Brand Matters: Brand Authenticity and the Family Firm Trust Inference. Journal of Business Research, 89, 121-134. https://doi.org/10.1016/j.jbusres.2018.03.040

[62] Hargis, M.B. and Bradley, D.B. (2011) Strategic Human Resources Management in Small and Growing Firms: Aligning Valuable Resources. Academy of Strategic Management Journal, 10, 105-125. http://www.thecasecentre.org

[63] Popescu, C.C. (2018) Improvements in Business Operations and Customer Experience through Data Science and Artificial Intelligence. Proceedings of the International Conference on Business Excellence, 12, 804-815. https://doi.org/10.2478/picbe-2018-0072

[64] Huete-Alcocer, N. (2017) A Literature Review of Word of Mouth and Electronic Word of Mouth: Implications for Consumer Behavior. Frontiers in Psychology, 8, 1-4. https://doi.org/10.3389/fpsyg.2017.01256

[65] Kujur, F. and Singh, S. (2016) Social Media as an Enabler of Marketing Strategies. International Journal of Economic Research, 13, 373-381.

http://www.ijeronline.com/

[66] Xie, H., Li, X., Wang, T., Chen, L., Li, K., Wang, F.L. and Min, H. (2016) Personalized Search for Social Media via Dominating Verbal Context. Neurocomputing, 172, 27-37. https://doi.org/10.1016/j.neucom.2014.12.109

[67] Rajasekaran, R. (2015) Starbucks' Entry into Tea-Drinking India. IUP Journal of Brand Management, 12, 45-58. http://www.iupindia.in/Brand_Management.asp

[68] Situmorang, S.H., Mulyono, H. and Azmi, A. (2018) Effect of Servicescape and Customer Experience on Social Location Marketing (Case Study at Café in Medan). Advances in Economics, Business and Management Research, 46, 546-552. https://doi.org/10.2991/ebic-17.2018.86

[69] Porter, M.E. (1980) Competitive Strategy. Free Press, New York.

[70] Zeriti, A., Robson, M.J., Spyropoulou, S. and Leonidou, C.N. (2014) Sustainable Export Marketing Strategy: Fit and Performance. Journal of International Marketing, 22, 44-66. https://doi.org/10.1509/jim.14.0063

[71] Ogbuji, B. and Papazafeiropoulou, A. (2016) Social Media Strategies for Companies: A Comprehensive Framework. Lecture Notes in Computer Science, 9844, 3-14. https://doi.org/10.1007/978-3-319-45234-0_1

[72] Van der Merwe, K. and Maree, T. (2016) The Behavioural Intentions of Specialty Coffee Consumers in South Africa. International Journal of Consumer Studies, 40, 501-508. https://doi.org/10.1111/ijcs.12275

[73] Stephan, U., Patterson, M., Kelly, C. and Mair, J. (2016) Organizations Driving Positive Social Change: A Review and an Integrative Framework of Change Processes. Journal of Management, 42, 1250-1281. https://doi.org/10.1177/0149206316633268

[74] Yuen, F. and Johnson, A.J. (2016) Leisure Spaces, Community, and Third Places. Leisure Sciences, 39, 295-303. https://doi.org/10.1080/01490400.2016.1165638

[75] Chua, A.P.H., Deans, K.R. and Parker, C.M. (2015) Exploring the Types of SMEs Which Could Use Blogs as a Marketing Tool: A Proposed Future Research Agenda. Australasian Journal of Information Systems, 16, 561. https://doi.org/10.3127/ajis.v16i1.561

[76] Stock, R.M., de Jong, A. and Zacharias, N.A. (2016) Frontline Employees' Innovative Service Behavior as Key to Customer Loyalty: Insights into FLE's Resource Gain Spiral. Journal of Product Innovation Management, 34, 223-245.

https://doi.org/10.1111/jpim.12338 